\title{
Good Teachers: Visions of Values and Virtues in University Student Metaphors
}

\author{
*MARTIN CORTAZZI ${ }^{1}$ \\ LIXIAN JIN ${ }^{2}$ \\ ${ }^{1}$ Centre for Applied Linguistics, University of Warwick, Coventry CV4 7AL, United Kingdom \\ ${ }^{2}$ School of Education and English, University of Nottingham Ningbo China, 199 Taikang East \\ Road, Ningbo, China \\ *Corresponding author: M.Cortazzi@warwick.ac.uk
}

Published online: 20 October 2020

To cite this article: Martin Cortazzi and Lixian Jin. 2020. Good teachers: Visions of values and virtues in university student metaphors. KEMANUSIAAN the Asian Journal of Humanities 27(2): 145-164. https://doi.org/10.21315/kajh2020.27.2.8

To link to this article: https://doi.org/10.21315/kajh2020.27.2.8

\begin{abstract}
Good teachers in university education embody combinations of continuity and change. In the first part here, university teaching is considered in Western philosophies and educational discourse to suggest teacher characteristics and meta-functions, but this article proposes wider internationalised dialogues within humanities which crucially take student views into account. In the second part, we analyse a database of 863 metaphors about teachers given by 439 university students in Malaysia, adopting a socio-cultural approach based on cognitive linguistics. This elicited metaphor analysis explores student views of "good" teachers expressed in such metaphors as "a good teacher is a burning candle" or "a piece of chalk". Our analysis of metaphor entailments reveals meta-functions and virtues of good teachers which though absent in some official discourses, cohere with the educational philosophy of part one: they include cognitive, social/cultural, affective, moral/ spiritual and aesthetic meta-functions. These emphasise the purposes of what teachers "do" and the character of what teachers "are", as models for what students "do" and what they "become". This gives challenging insights for teachers (and students) to self-cultivate virtues if these participant visions are taken seriously for learner-centred approaches to humanities in new balances of continuity and change.
\end{abstract}

Keywords and phrases: metaphor analysis, philosophy, good university teachers, metafunctions, journeys of learning

\section{Introduction: Continuity, Change and Universities}

Stability and change are binary opposites in much Western either-or thinking, but in classical Eastern philosophies, such as those of India and China, they co-exist 
in tension, as necessarily complementary. Eventually, each generates the other in a blended dynamism. The Mexican poet and Nobel Laureate, Octavio Paz (19141998), during his visit to a temple at Jaipur, India, meditated on Hindu visions of what seems fixed and the process of change.

Fixity is always momentary. It is an equilibrium, at once precarious and perfect...each change here brings about another change there...change is comprised of fixities that are momentary accords... Wisdom lies neither in fixity nor in change, but in the dialectic between the two... (Paz 1990, 9-10)

Paz does not mention teachers: he philosophises on the nature of language and of metaphors, which are used here as a lens to focus on visions of good teachers in universities. For teachers, fluctuating combinations of fixity and change are normal. After all, the continuity of knowledge transmission and socialising learners into disciplinary values, together with changes through transforming minds and communities via new knowledge and understanding are two enduring purposes of university education. Currently, members of the academic profession know that teaching is itself only one component of momentary accords between teaching, research, administration and bureaucracy and more recently income generation and entrepreneurship, but for most students teaching-and-learning is at the centre of a university. Current official discourses of good teaching often stress the need for innovation, lately in uses of newer technologies and online classrooms or in the need for teachers to develop more learner-centred approaches, together with student autonomy and independent learning. These are among recent official emphases in Chinese universities in which teachers aim for "a gold standard" (Jin and Cortazzi 2020).

Worldwide, apparently measurable ways of assessing teacher competencies have been established as part of ranking institutional teaching quality within university systems. Students access this public information; it is often circulated within a university's marketing. In the Teaching Excellence Framework (TEF) in the United Kingdom (UK) (TEF 2016), these ratings can include achievement outcomes and rates of graduate employment and earnings (students may think "a good teacher helps us pass exams and get well-paid jobs") or student satisfaction ratings of teaching ("a good teacher gets high student feedback scores"). Teaching assessment is based on national data and a university's written submission related to the whole institution, but is not yet related to disciplines or courses and not at all to individual teachers. Beyond statistical responses to standard questionnaires on "satisfaction", the relation to participant ideas about teaching quality is opaque: staff and students are not asked what good teaching is. 
However, university staffs do have long-standing beliefs about goals of teaching which likely evolve in changing contexts. Glimpses of these occur in mission statements. A British analysis of such statements summarises a broad view of how, besides students' cognitive development, university teachers aim at their emotional and moral development, aesthetic sensibility and creativity, developing practical competence and citizenship values (Allen 1988). This suggests an institutional view of meta-functions - good teachers should develop these in students; they frame the practical teaching of disciplines.

Yet there is no single model of "a good teacher", rather, there are different discourses in some Western ideologies which predominate at different times (Moore 2004): first, a good teacher as "a charismatic person", who inspires, nurtures and cares for students; and second, as "a competent craftsperson", a knowledgeable technician skilled in pedagogic strategies, who plans, manages and assesses learning and third as a "reflective practitioner", a thoughtful agent who meets challenges and creates significant change by reflecting on pedagogic problems to develop solutions. However, while these three discourses cohere with interview data with postgraduates training as teachers (ibid.), students in general are not asked.

Some continuity is seen in a chronological thread of some Western philosophies regarding universities and roles of good teachers. This perspective helps to balance current official discourses, as argued by a teacher-training historian: "There is, perhaps, no more liberating influence than the knowledge that things have not always been as they are and need not remain so" (Simon 1966, 92). In the changing orientation towards more student-centred approaches, the students' perspectives on good teachers should be influential.

This article considers Western philosophical accounts of universities and teaching which are then related to the context of Malaysia before turning to student metaphors of good teachers. These are analysed using the linguistic method of elicited metaphor analysis to show a range of Malaysian students' views and values about good teachers, which are briefly related to student learning.

\section{Some Western Thinking about Universities and Good Teachers}

Some Western philosophers have combined continuity and change in their questioning about the basic meanings of "university" and "teaching". Alongside intellectual functions, cardinal features include culture, moral values, wisdom and even aesthetics. The English poet, John Milton (1608-1674), argued that universities should aim to develop students' "physical, intellectual, moral, religious and aesthetic abilities" (Milton 1644), while Saint John Newman (1801- 
1890) held that universities are institutions of intellectual culture "to educate the public mind" and teachers should provide students with "freedom, calmness, moderation, wisdom" (Newman 1908). The Spanish philosopher José Ortega y Gasset (1883-1955) argued that university teachers should prepare students for scientific research and for the learned professions, but, equally, they should teach and transmit culture and its interpretation. By "culture", he meant "the system of vital ideas which each age possesses...the hierarchy of the values of things...the totality of what we do and what we are" (Ortega y Gasset 1944, 70-73). Teachers should be selected for their gift for teaching (rather than for research) and "teaching must be based upon the student" (ibid., 52). Of international influence were the academic ideas for German universities of Wilhelm von Humboldt (1767-1835), who proposed the unity of research and teaching in a holistic approach to teach arts, cultural knowledge and sciences in order to cultivate students' minds and characters towards world citizenship, thus to handle the big questions of humanity (McClelland 1980). A central concept was Bildung (an untranslatable German term combining education, character formation, self-cultivation, all related to culture and civilisation), a rounded humanistic education in which "the highest and most harmonious development of natural human abilities" was developed in teaching seminars "characterised by active dialogic creation that included both teachers and students" - these aimed "to produce student character and action, not superficial knowledge and empty talk" (Östling 2018, 38-41). Extending this, the German philosopher, Karl Jaspers (1883-1969), emphasised how a good university teacher in a community of scholars engages students in Socratic dialogue, treating them as independent learners, to seek truth and transmit learning and culture: the idea of the university depends upon individual teachers (Jaspers 1960). Jaspers saw three strands of university education - a stable one looking back to old certainties, a second concentrating on narrow skills training and a third pursuing constant innovation (Jaspers 1951, 105) — good teachers surely combine these. University traditions, such as Bildung, have to be kept alive by being constantly connected to what is new (Östling 2018, 71). The English philosopher, Mary Warnock (19242019), argued that good university teachers are knowledgeable, imaginative, innovative and creative, part of an intellectual community. They emphasise not so much knowledge as such but rather the process of acquiring knowledge to understand disciplines, relate them to each other and apply principles. They lift students out of intellectual and imaginative limitations and develop critical insights to understand the ecological, social and political environment. Good teachers, she said, are interested in their students as much as in their subjects. As intellectual innovators, they give students experience to participate in innovations to expand imaginative horizons (Warnock 1989, 21-37). 
Figure 1 summarises these key "Western" ideas and it highlights from the philosophical literature "meta-functions" of good teachers: cognitive, affective, socio-cultural, moral-spiritual and aesthetic. These also emerge in our empirical metaphor analysis, reported below. Apart from the aesthetic meta-function, they are evident in contemporary non-metaphor investigations of good teachers, such as studies of language teacher identity in which such identities,

are both cognitive and social and they are closely associated with emotions and what they think and feel about their practices... a teacher's professional identity is interrelated with their personal identity... [and] a teacher's moral stance. The question of values, moral visions, ideologies and ethical judgement is inherent in virtually every aspect... (Barkhuizen and Mendieta 2020, 4-6)

A GOOD TEACHER in universities is striving to be ...

knowledgeable, imaginative, innovative, inspiring, creative, caring, nurturing, calm, moderate ...

CULTIVATES VIRTUES, to enable teaching excellence, of ...

humility and courage, independence and open-mindedness, empathy and enthusiasm, judgment and imagination, wisdom ...

FOCUSES ON DEVELOPING STUDENT skills, knowledge, understanding related to ... knowledge and intellectual abilities (cognitive); emotions (affective); social, ecological and political understanding, citizenship, cultural knowledge and values (social-cultural); students' character, moral and religious values (moralspiritual); aesthetic and creative abilities (aesthetic); practical competences for a profession; physical abilities ...

ENGAGES IN TEACHING which ...

is based on the students - treating them as independent learners, emphasises the process of knowledge acquisition, engages students in active dialogues and innovations

Figure 1. Characteristics of good teachers highlighted in educational philosophies (meta-functions are in italics)

Such theoretical notions are therefore not simply remote philosophies of the past: they have become deep-rooted as ideas and ideals which affect current official thinking in universities, including current developments in China (Jin and 
Cortazzi 2020). They are even evident in national questionnaire surveys of student satisfaction. In the UK, such a survey includes items to ask students for their ratings of teacher "explanations", making subjects "interesting" and being "enthusiastic about teaching content"; however, the last item was dropped in 2017 which suggests a shift in ideas about teacher knowledge, while items about "feeling part of the learning community" and valuing "student views and opinions" as part of "student voice" were added (Office for Students [OFS] 2020). The "learning community" is a clear echo of Bildung and Warnock's (1989) "intellectual community" concept. Somewhat differently, but also showing this continuity, is a university student satisfaction survey in one Malaysian university (there is currently no national survey as such) which includes items on teachers' "knowledge of subject matter", "presentation skills" and "helpfulness and politeness" (Rohayati, Rajadurai and Salina 2007). Such surveys are becoming significant in university rankings, with overtones of public accountability and value for money paid as fees for teaching, rather than of visions of values and virtues, but the UK survey does include "the student experience", "learning from other students" and "the student voice" as key elements (OFS 2020), with resonances from Ortega y Gasset (1944) and Jaspers (1951). Meanwhile, other recent international research into good language teachers (Griffiths and Tajeddin 2020) includes case studies in Turkey, Iran, Nepal, Myanmar, Singapore, Indonesia and Vietnam, besides Eastern and Western Europe, and South America - overall, they emphasise a range of teachers' personal qualities and relevant teacher knowledge and skills, which is consistent with the above philosophies.

Each of the above philosophical strands is serially reinterpreted or reconstructed in changing contexts. This stance echoes Paz's dialectic of wisdom between fixity and change, but wisdom is not the only virtue which is pivotal here. Other key virtues are not so much as markers of achievement of particular good teachers as ideals for practice, the development of which "enable" all teachers to achieve excellence. This conception is developed by the contemporary Canadian philosopher, William Hare $(1993,162)$, "Our notions of the 'good teacher' need to shift from behavioural criteria to more fundamental human excellences". Hare elaborates this in detailed discussion of how teachers need to cultivate pairs of virtues: humility and courage, impartiality and open mindedness, empathy and enthusiasm and judgment and imagination. These virtues complement and support each other. Good teachers are therefore learners making efforts to cultivate in themselves (and for their students) such professional and personal virtues, in what they "do" and in what they "are becoming". While these sources indicate some "Western" agreement about good teachers (as shown in Figure 1) and they may inspire foundational thought for teacher development in Malaysia, worldwide there are different emphases across philosophies, geographies and discourses and cultures. This indicates potential 
learning in international dialogue about good teachers. For example, some Western institutions might gain insights from Confucian educational traditions in China which give a key role to self-cultivation of virtues (Jin and Cortazzi 2008; 2020), which are seen in over-arching characteristics of good teachers who embody knowledge, cultivation and morality (Cortazzi, Jin and Wang 2009).

Some variations within such continuities will accord with national policies or suit local practices in given institutions or particular university departments. In Malaysia, university developments show an interweaving of four influences. First, the colonial heritage of British universities, transformed to restructure the post-colonial society; second, the global trends of modernisation and internationalisation, which affect competition and collaboration between universities and therefore influence teachers to enact relevant pedagogies; these are modified by a third influence in indigenous developments to build capacities to serve family, community and nation and to teach students as holistic and well-balanced graduates; this is further influenced by Islamic conceptions of applying knowledge in service, not only in Islamic universities (Kim 2001; Wan, Morshidi and Dzulkifli 2015; Lee, Morshidi and Wan 2017). This fourth influence is not always acknowledged in university histories in Europe, although Islamic higher education institutions were established decades before those of Europe (in Baghdad, Cairo, Tunis and Fez) and through their international students they disseminated to Europe a cultural ethos of high-quality learning and high reputations of teachers (al-Hassani, Woodstock and Samad 2007). This article reports research into the perceptions of "good" teachers by students in universities in Malaysia.

\section{Elicited Metaphor Analysis}

Metaphor is a basic part of our conceptual systems. There is ample evidence that through analysing the language of commonplace metaphors the underlying concepts held by metaphor users can be analysed (Lakoff and Johnson 2003; Gibbs 2017), which can be universal or culturally specific (Kövecses 2005). Researchers using elicited metaphor analysis collect metaphors given by participants themselves (rather than metaphors found in a corpus of existing texts, such as policy documents or university statements) to examine fundamental concepts and social values in education and other fields (Cortazzi and Jin 1999; 2020; Wan and Low 2015). This approach has been used here with large metaphor databases to explore conceptualisations of teachers in China (Cortazzi, Jin and Wang 2009; Jin and Cortazzi 2020) and Iran (Cortazzi et al. 2015) and of student learning in China (Jin and Cortazzi 2011a; 2011b; Cortazzi and Jin 2018). The cited philosophical dimensions or teacher meta-functions turn out to be systematic themes in metaphors 
in China and in Iran (Cortazzi et al. 2015; Cortazzi and Jin 2019), which are participant-driven data expressed in students' own words.

This method can be briefly outlined. Metaphor is one kind of analogical thinking in which something under discussion ( $X$, usually abstract or complex) is compared to something else ( $Y$, usually more familiar, immediate or concrete): As Paz (1990, 159) puts it, "Analogy: universal transparency: seeing in this that". Here, the topic of "a good teacher" ( $X$, the "target" of the comparison) might be compared to "an old cow" ( $Y$, the "source" from which ideas are transferred to the target). But in research, it may not be simple or obvious to identify what participants mean by "My teacher is an old cow" - Which features of an old cow are like the teacher? This example shows the need to get participants' own interpretations. In the UK, this metaphor is an explicit negative evaluation of a teacher (who is portrayed as unpleasant, stupid, ugly in a gender-based insult) whereas in China what is apparently the same metaphor expresses praise and admiration (the teacher is hardworking, tirelessly productive, serving people and suffering in silence); relatedly, "an ox" for Buddhists can represent in stories and art one's true self (so the teacher is guiding learners to search for, find and live their true Buddha-nature) while in India, "a cow" is well-known as a sacred symbol (so, the metaphor represents the holiness of a teacher). Crucially, then, this method asks participants for reasons for their metaphors ( $X$ is $Y$ because $Z$ ) and thus the reason ( $Z$, the "entailment") is as much the basis for analysis of the target $X$ as the source $Y$. Without considering the entailments, there is a risk that the researchers impose unintended meanings on the metaphor data. We use a simple proforma of "A good teacher is $\mathrm{Y}$ because Z" - "A good teacher" is the target; students give their own sources in up to three metaphors in an open-ended format in which they can make any comparison; students add their own entailment, writing their own explanation.

Using an open-ended format to elicit student metaphors, we analyse 863 metaphors for "teachers" given by 439 students, in English, in three well-known universities in East and West Malaysia, with some reference to a further 640 metaphors given by the same students for "student learning". Students ( 235 female and 90 male) were studying undergraduate and postgraduate courses in English, applied linguistics, education, business and health care. The respondents represented the linguistic diversity of first and other languages (other than English) commonly found in Malaysian universities (we did not investigate ethnicity or religious affiliation). Thus, there were numerically dominant numbers of speakers of Bahasa Malaysia, large numbers of Chinese speakers (Mandarin and dialects), a fair proportion of speakers of Indian languages, besides a minority of speakers of Arabic, Persian, Japanese, Korean and others. This spread of languages indicates a likely range of ethnicities, including those of some international students and therefore the 
possibility of linguistic-cultural variations within the datasets. This is recognised and while a future study might explore possible ethnic-cultural variations we have treated the current data as representing current student cohorts of the Malaysian universities, which embrace such diversity. The method described above ensures that if, say, several students give a few quite different metaphors this does not affect the results since the method focuses on combinations of metaphors and patterns of entailments from many participants which are analysed to reflect larger trends.

This method and the extensive present data-base overcome some limitations of other studies. For example, the seminal study by Oxford et al. (1998) draws on 250 narratives about teachers by students, but the analysis reveals only 14 distinct metaphors which do not necessarily elaborate the entailments and these are categorised into a typology of "four different philosophies of education" (Social Order, Cultural Transmission, Learner-Centred Growth and Social Reform). These accord well with the philosophical literature reviewed here. However, given that any metaphor may have and normally does have, a range of entailments and therefore clusters of different meanings, the classification risks a top-down researcher interpretation which interestingly elaborates and illustrates each philosophy but it is unknown whether the interpretation accords with what the metaphor-makers had in mind since such meanings are rarely elaborated in narratively-occurring metaphors (cf. previous "My teacher is an old cow") (Cortazzi and Jin 2019; 2020). A study of 23 Malaysian university students' metaphors for language teachers of Russian (Nikitina and Furuoka 2008) follows up the Oxford et al. (1998) typology by analysing 27 elicited metaphors, with their entailments, into three of the above philosophies (no metaphors matched Social Reform) and explores gender variation. In our experience, though, an elicited metaphor dataset really needs to include hundreds of metaphors from hundreds of participants (Cortazzi and Jin 2019; 2020; Cortazzi, Jin and Wang 2009; Cortazzi et al. 2015).

A possible objection to this elicitation method relates to the status of metaphor data: are they real, creatively imagined, socially agreed, individualised or idealised? As with much survey and interview data, in elicited metaphor data analysis it is sometimes difficult to separate passing opinion, actual beliefs or behavioural correlates. A metaphor analysis may reveal commonly-held cultural ideals about teachers, but many student metaphors are explicitly given with real teachers in mind (sometimes named) and some negative or humorous examples (if not most examples) are based on experience. While some elicited metaphors are certainly creative and innovative (especially considering that they are given in English), what matters is the entailment in the target-source-entailment relation. There are considerable commonalities among the entailments, which suggest socio-cultural conceptions rather than simply personal ones (Cortazzi and Jin 2020). There is 
some confirmation, too, from classroom observations and photos of teachers and learners enacting certain metaphors in behaviour, stance and gesture. Further, there are well-known sayings, proverbs and classical literary citations which show identical metaphors, at least in China, which suggests some continuity of metaphor tradition (Jin and Cortazzi 2008); there is also some consonance between official metaphors for teachers, documented over decades and students' elicited metaphors and between university teachers' and students' metaphors (Jin and Cortazzi 201 1b).

\section{Malaysian Metaphors for Good Teachers}

These metaphors from Malaysia encompass an enormous variety of sources for the target. Many seem innovative and imaginative: "A good teacher is a wheelchair, an umbrella, a washing machine, a laptop, a machine gun, sweet honey, a great heart, a true companion, a window on the world". These would be challenging to analyse (though some seem to have guessable meanings) without attending closely to the entailments, which are far more restricted in range. Here, we focus on participants' entailments. Importantly, our analysis never depends on a single metaphor, even if this is given by several or many students independently - an analysis might otherwise appear arbitrary or based on just a few student responses. Rather, we look for similarities across metaphors and for meanings across entailments. Thus, the metaphors for a teacher as "a sun", "a lantern", "a father", "a wallet" or "a piece of chalk" can appear somewhat random or unrelated to each other. However, an examination of the entailments given by the participants in their own words shows overlaps or networks of meanings: A good teacher is "a sun: they give out all of themselves to teach us", "a lantern: they burn themselves to light up others", "a father: they sacrifice everything for their children (students)", "a wallet: they fill themselves with valuable things but constantly give out what they have to spend it on others" and "a piece of chalk: the chalk gets shorter the more knowledge it writes for students, the more knowledge they gain, the more the chalk is worn down". It is apparent that these all relate to teacher giving, teacher-burning, in self-sacrifice, with very similar entailments. While there are just a handful of the above in the database, there are 84 metaphors of "A good teacher is a candle", many also explicitly featuring sacrifice, which indicate how teacher dedication, devotion and sacrifice are salient for these students. "A teacher is a candle burning its wick because they sacrifice themselves for students". This is a major feature of perceptions of good teachers in metaphors in Asia and the Middle East, but there is a dearth of mention of teacher devotion and self-sacrifice in official education discourses.

Some metaphors portray teachers in virtue-laden terms: "A good teacher is: 'a mountain of virtue: they have patience, kindness', 'they're role models that shine 
through the darkest night' and 'they reflect their best characters to us"'. Among 30 metaphors about "prophets", "angels", "gifts from God", "noble people", "saints" and "saviours", teachers are "so kind", "very patient", "holy", "they bring sunshine and rain", "they rescue us from the darkness of ignorance", "teach with love and passion", "give us inspiration", "lift up our spirit" and "bless us with the most precious gift of education". They are "angels: because it's a noble job" and "their knowledge exceeds everything and they can take us to heaven". These metaphors have obvious religious sources. Some have salient religious contexts of meaning: "A teacher is an honourable person; the work of a teacher is ibadat (a religious act of devotion in Islam) to develop humans who are useful". Further, religious resonances within Islam are heard in many phrases about teachers who "guide us in the right path", "lead us to the right path in the darkness" and "show us the right way" (cf. Qur'an, Surah al-Fâtihah, verse 6) and there's a reference to a famous Buddhist parable in "A good teacher is a boat: with it you can cross the river of illusions (maya) and reach the ultimate truth and self-enlightenment".

A few metaphors show teachers in a negative or mixed light. A few teachers are "a nightmare", "a devil", "an anti-hero: some manipulate and abuse their security". "Teachers are a mum: always nagging and babbling", "they like to mumble a lot", "a nagging granny, very long-winded", "they're always moody and change direction like the wind" and "sometimes they are fierce and angry". "A teacher is a volcano: if it erupts everyone will have to endure the catastrophe", "they can be a friend to you, but also your enemy" and "they either enlighten you or destroy your life".

The student metaphors for good university teachers can be analysed to show how these teachers in their practices demonstrate combinations of meta-functions: these were illustrated in philosophical thinking (as shown in Figure 1). This shows a possible continuity that students' thinking, revealed in entailments of their metaphors, could also be rooted in similar meta-functions. However, this continuity is likely indirect, since few of these students have studied such educational philosophy. In Malaysia, there are, of course, more traditional Western and contemporary international influences on teaching in universities, including such meta-functions and over the years many Malaysian teachers have studied in the West and perhaps these are influences for students, or, additionally and significantly, these meta-functions are possibly inherent in recognising good teaching, with cultural variations.

Examples of these meta-functions, widespread throughout the metaphor database, are shown here in students' words: 
1. Cognitive: Good teachers "lead students to a different world of knowledge"; "open the door of knowledge for us"; "provide knowledge that gives power"; "their knowledge flows onwards"; "they light up our life with knowledge and wisdom".

2. Affective: Good teachers "care for us"; "are always pouring out care"; "shine kindness upon us"; "suddenly motivate me when I need it", "motivate you to be successful in your life", "energise their students", "teach us from the heart"; "their every word comforts my heart", "they love their students"; "because we are taught with love and care", "they teach me how to love people".

3. Social-cultural: Good teachers "bring many generations into a successful life"; "make us laugh"; "are a dictionary of knowledge and culture"; "light up ALL students"; "they light up so many lives", "they can save our country"; "they transfer knowledge from generation to another"; "they are the pulse of the nation because without them we are useless";

4. Moral-spiritual: Good teachers "build up students' characters so they become better people"; "they correct our mistakes", "teach us wrong from right"; they "right our wrongs"; "show us the right path in our life"; "guide us to the right path"; "guide us to the right way"; they are "my role model", "they show us the lights of wisdom and give us enlightenment", "they brighten students' soul".

5. Aesthetic: Good teachers "are always beautiful"; "dress beautifully"; "the most beautiful elegant person I have ever known"; "give us a nice view of the world by showing us beauty"; "they paint the world for us beautifully", "they paint our lives in beautiful ways"; "they show you ideas beyond your imaginings", "they inspire our creative and innovative mind"; "a beautiful teacher is beautiful from his / her character".

These meta-functions often overlap or are combined to reinforce each other: "Good teachers have heart, passion, emotion (affective) to fine tune an idea (cognitive) into a beautiful product (aesthetic)". The meta-functions can be seen within the single metaphor of "A teacher is a burning candle", which is about sacrifice; however, there are clusters of underlying meanings.

The "burning candle" metaphor for teachers shows conjunctions of these metafunctions within a single metaphor. In participants' own expressions: 
1. Cognitive: "they give light to help students become more knowledgeable", they burn themselves to enlighten our knowledge", "they light up our life with knowledge and wisdom", "they brighten up the dark corners of our minds", "they light up our minds with knowledge by burning themselves out".

2. Affective: "they light up our hearts with education"; "they give us the spirit to study", "they give students the warmth of life".

3. Social-cultural: "they burn themselves to benefit others, lighting up people's lives in society", "they enlighten everyone's life", "they burn themselves to make all their students succeed in this world".

4. Moral-spiritual: "they light us up to the right path in the darkness", "they burn themselves for the goodness of others", "they burn or sacrifice their time and give dedication to build up students' characters so that they become better people".

5. Aesthetic: "their light leads us to beauty".

The "burning candle" metaphors portray teachers as "hard-working", "using all their efforts"; "they struggle so hard", getting "exhausted" but "dedicating most of their life"; "they sacrifice themselves", "sacrifice everything", "sacrifice their lives". The expressed purposes are "to benefit others", "thorough learning and enlightenment", "to show the way, to light up the path", "to bring knowledge and success" and "to ensure students' future success". This dedication and sacrifice are therefore intimately linked to students' journeys of learning and their destinations.

This analysis of the burning candle metaphor adds an innovative balance to the conception of "teacher burnout", which is related to the occupational demands and stresses of teaching. Teacher burnout is defined as a state of emotional exhaustion with depersonalisation and reduced personal accomplishment; this is a major factor with a negative effect on teacher performance and which negatively affects students' learning (Griffiths and Sönmez 2020). On the contrary, the "burning candle" metaphor shows learners' deep appreciation and admiration for teachers' accomplishments through sacrifice, recognising their heavily-loaded demands of work and often their suffering. This suggests that teacher well-being could be supported, even ameliorated to avoid burnout, by officially recognising and rewarding teachers as positively enlightening "burning candles".

The metaphors show features of continuity and change: "A good teacher is a river: they it keeps flowing forever even when there's a rock in front", "they never stop 
showing us the right way"; "they inspire our creative and innovative mind", a good teacher is "a moon: their mood can change every day", "a wind: they are always moody and change like the direction of the wind", "a chameleon: they seem to change their methods and personalities according to the class they are in", they are "a wheel: sometimes we are at the top, sometimes we are at the bottom" and "they are the seasons: they have to be cold in winter, hot in summer, warm in spring and windy in autumn".

Part of the changing role of teachers in these metaphors is to develop learner effort towards independence to be creative with their own vision: "they teach me how to learn", "they only lead you to the well of knowledge - you have to use your own bucket to draw the water", "I follow their footprints until I create my own footprints" and "a good teacher is a lamp in the dark: they chase us out from the dark side - you do not need the lamp once you are in broad daylight".

Good teachers, in metaphors, are highly active facilitating and supporting models of humane qualities. They "show care, concern, calmness, patience, warmth, passion, wisdom". They "give priceless knowledge, inspiration, hope, love, happiness, strength, protection, shelter" and they also "help students to discover and learn, to grow up and develop, to move to a higher level, to face the challenges of life, to realise what they are capable of and how far they can go". In this, "they make students smile, laugh and students become cheerful, happy, energetic and dynamic", "they instil interest and motivation", "they build up students' better character, better knowledge" and "they scaffold students' growth and progress" (as shown in Figure 2). 


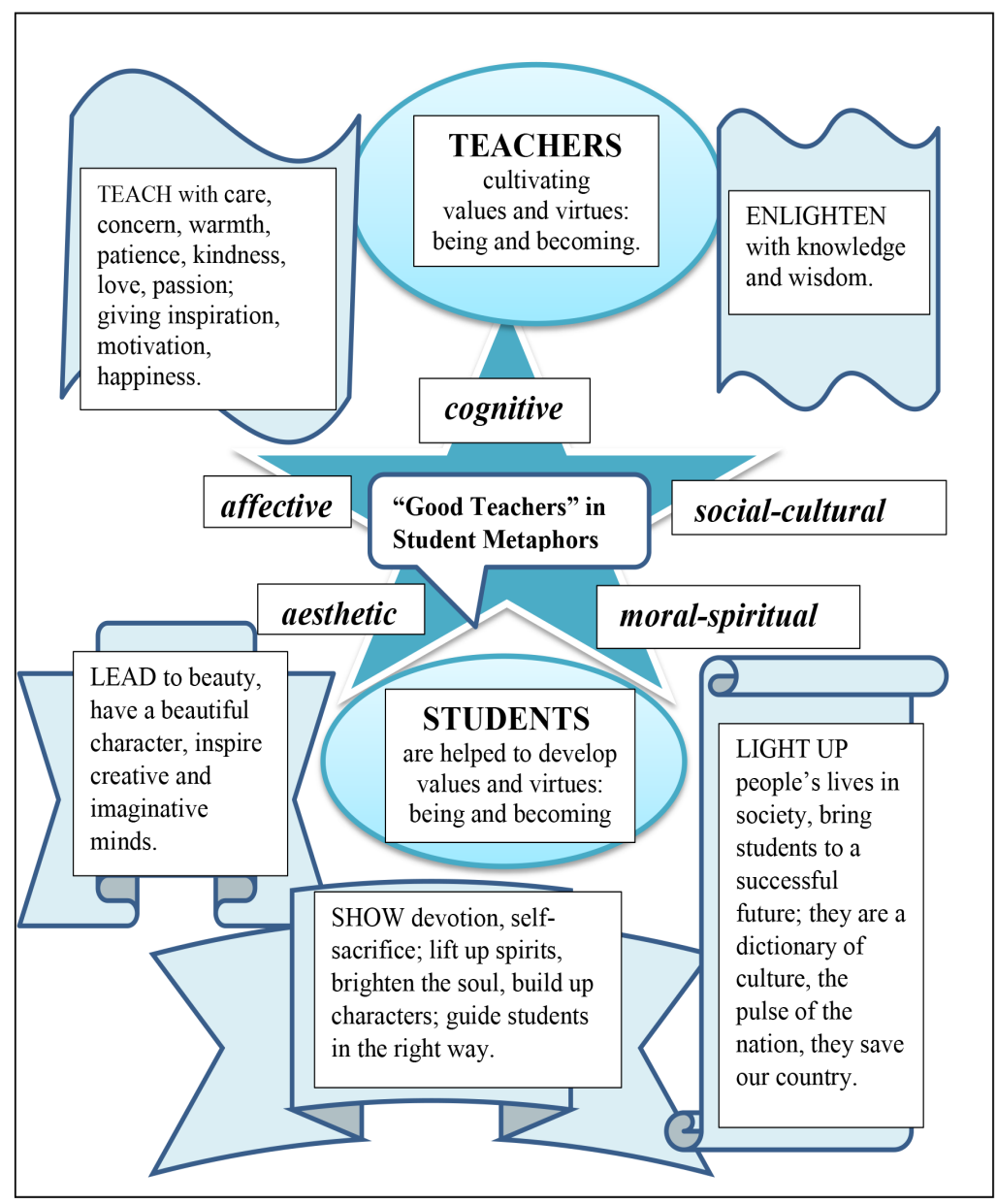

Figure 2. Meta-functions in expressions in Malaysian students' metaphors for good teachers found in this study

\section{Malaysian Students' Journeys of Learning and Teachers' Roles}

Above all, these good teachers help students in their journeys of learning. This is evident when "a good teacher is a bus: they bring their students along the journey of learning, discovering", "a driver: they drive me until I reach the end of my journey" and "an energy bar: they give you strength in your journey to gain knowledge". This is frequently seen in the spatial orientation and forward movement to a goal: "they guide me in the way", "lead us on in our life", "open the way to all sorts of opportunities", "give direction to reach a destiny" and "take students to a bright future and successful life in this world". 
These roles are confirmed in students' metaphors for learning, given independently of the good teacher metaphors, in which there are 34 metaphors of "learning is a journey", with 31 related ones of "learning is a road" and 24 of "learning is climbing a mountain" or "climbing "stairs" or a "ladder". In these, "learning" is "a process" which "takes us ahead", "always moving forward", "we learn step by step" and "every step count." The journey is "endless", "continuous", "lifelong", "infinite" but also "beautiful" and "wonderful"; it is "a road of hope", "amazing and exciting"; students "have to keep going", they "should not give up" although "it takes a lot of effort" because "it is a struggle", "full of ups and downs" with "thousands of obstacles". The final destination is "new knowledge" (cognitive), "the end point that we dream of... it leads us to our dreams.... we will experience every emotion" (affective), it connects us to other people ... we gain knowledge from having interaction with others" (social, cognitive), it is "a beautiful journey ... it leads us to beauty" (aesthetic), "you do not have to reach your destiny but it gives you knowledge and experience to make you a better person" (cognitive, moral) and on the journey, "we can improve ourselves every day, take the right way, it will lead us back to our Creator" (moral, spiritual).

Crucially, in students' metaphor expression about journeys of learning, teachers are essential: "without teachers' assistance we won't reach our destination", "our teachers want us to fly as high as possible", "without them you can't learn anything", "without a teacher, none of us would be the person we are today" and "they will be with you until the day you die".

\section{Conclusion}

A vital element within local changes in viewing good university teachers is the need to value international visions of diversity in philosophies, histories and contexts. Visions also need to centre on student-participant expectations and experiences of good teachers, on what teachers "do" and who they "are" or who they "are becoming", in their profession and in their personal character. This article therefore suggests the need to elaborate two kinds of dialogue of visions and values: one between international philosophies of educational thinking and conceptions of good teaching within humanities (a more theoretical or perhaps top-down approach) and another between teachers and students regarding students' and teachers' own expectations, especially where there is diversity among participants, say with international students and staff (a more data-driven, bottom-up approach). The two parts of this article show possibilities of dialogue between these approaches, as well as within each of them. From the viewpoints of Malaysian policy makers and practitioners, the article illustrates some significant commonalities between features of Malaysian universities and educational thought internationally, while 
importantly showing how Malaysian policies and practices might adopt their own local stance, for example towards combinations of the meta-functions shown in this study.

In this article, some Western philosophers and university educators show the continuity of the meta-functions of good teachers as illustrated here: cognitive, affective, socio-cultural, moral-spiritual and aesthetic (as shown in Figure 1). It seems an innovation to show that these are deep-rooted among students in their metaphors for good teachers (Cortazzi et al. 2015; Jin and Cortazzi 2016, 2020; Cortazzi and Jin 2018), here given by participants in Malaysia (few students would be acquainted with the philosophical literature).

The data analysis here shows some commonalities with metaphors from China and Iran (e.g the salient "burning candle" metaphor), but there seem to be different emphases in the combinations of meta-functions. The Malaysia students' metaphors here show a dominance of the knowledge meta-function, substantial emphasis on affect and the moral-spiritual meta-function, but less on the socialcultural and aesthetic ones. Religious references are highlighted by some students, others stress family metaphors and goals of future success in more worldly terms. Possibly, this reflects personal variations among groups of individuals and perhaps the diversity of the student cohorts: although we did not investigate ethnicity, there is an apparent greater linguistic diversity of languages spoken among respondents (other than English) than among Chinese and Iranian students in our databases.

This conception of teacher meta-functions (as shown in Figure 2) is surely a point for the professional learning of teachers, though it raises challenges in humanities disciplines in any university to ensure engagement of all of these meta-functions with students in a holistic approach to daily pedagogic practices. These student metaphors for good teachers harmonise with those educational thinkers to show the value of a historical continuity of perceptions of teacher virtues. Yet, if university teachers and leaders consider these metaphors in universities (as well they might for a learner-centred approach since these are student-originated metaphors), they would acknowledge and value the teacher devotion, hard work and hardship and sacrifice symbolised by "a good teacher is a burning candle".

It cannot be presumed that teachers have necessarily developed the meta-functions and virtues as a pre-condition for their teaching - not all are saints. Yet teachers cannot really help students to engage in these without their own simultaneous self-engagement - that is, a good teacher is engaged continually in their personal self-cultivation of these values and virtues, learning to cultivate them as part of continuing teaching, learning to help themselves in these respects as a way to 
serve others professionally in a virtue ethics (Higgins 2011). Thus, this kind of self-cultivation is ultimately aimed at other-cultivation (seen in the burning candle metaphors). The varied virtues and values shown by good teachers thus imply tensions between self- and other-cultivation to ensure good teaching practices. And there is surely a changing diversity of visions of practising these virtues. Octavio Paz, accepting the Neustadt Prize for Poetry, valued contrasting thoughts by commenting how plurality is universality and universality means acknowledging the admirable diversity of humanity and commented that "to acknowledge the variety of visions and sensibilities is to preserve the richness of life and thus to ensure its continuity" ( $\mathrm{Paz}$ 1982). These metaphor visions of values and virtues continue in changing balances of combinations, in Malaysia and elsewhere: they are not fixed, "fixity never is entirely fixity...it is always a moment of change. Fixity is always momentary" (Paz 1990, 23).

An element of innovation is to recognise the fixity in some students' momentary expression in metaphors, as one Malaysian student reflected on her metaphors "Teachers are the virtues of good values, for all they do each day is contribute and spread value".

\section{References}

al-Hassani, S.T.S., Woodstock, E. and Samad, R. 2007. Muslim heritage in our world, 1001 inventions. Manchester: Foundation for Science and Technology.

Allen, M. 1988. The goals of universities. Milton Keynes: The Society for Research into Higher Education and Open University Press.

Barkhuizen, G. and Mendieta, J. 2020. Teacher identity and good language teachers. In Lessons from good language teachers, eds. C. Griffiths and Z. Tajeddin, 3-15. Cambridge: Cambridge University Press. https://doi. org/10.1017/9781108774390.004

Cortazzi, M. and Jin, L. 2020. Elicited metaphor analysis: Approaching teaching and learning. In Handbook of qualitative research in education, eds. S. Delamont and M. Ward, 486-503. Chichester: Edward Elgar. https://doi.org/10.4337/978178897 7159.00054

- 2019. Journeys of learning: Dimensions of metaphor and narrative landscapes across cultures. In Narrative and metaphor in education: Look both ways, eds. M. Hanne and A. Kall, 164-176. London: Routledge. https://doi. org/10.4324/9780429459191-12

- 1999. Bridges to learning: Metaphors of teaching, learning and language. In Researching and applying metaphor, eds. L. Cameron and G. Lo, 149177. Cambridge: Cambridge University Press. https://doi.org/10.1017/ CBO9781139524704.011 
Cortazzi, M., Jin, L. and Wang, Z. 2009. Cultivators, cows and computers: Chinese learners' metaphors of teachers. In Internationalizing the university, the Chinese context, eds. T. Coverdale-Jones and P. Rastall, 107-129. Basingstoke: Palgrave Macmillan. https://doi.org/10.1057/9780230235007_7

Cortazzi, M., Jin, L., Kaivanpanah, S. and Nemati, M. 2015. Candles lighting up the journey of learning: Teachers of English in Iran. In English language teaching in the Islamic Republic of Iran: Innovations, trends and challenges, ed. C. Kennedy, 123-138. London: British Council.

Gibbs, R. J. 2017. Metaphor wars: Conceptual metaphors in human life. Cambridge: Cambridge University Press. https://doi.org/10.1017/9781107762350

Griffiths, C. and Sönmez, G. 2020. Burnout and good language teachers. In Lessons from good language teachers, eds. C. Griffiths and Z. Tajeddin, 80-92. Cambridge: Cambridge University Press. https://doi.org/10.1017/9781108774390.010

Griffiths, C. and Tajeddin, Z., eds. 2020. Lessons from good language teachers. Cambridge: Cambridge University Press. https://doi.org/10.1017/9781108774390

Hare, W. 1993. What makes a good teacher, reflections on some characteristics central to the educational enterprise. London/Ontario: The Althouse Press.

Higgins, C. 2011. The good life of teaching, an ethics of professional practice. Chichester: Wiley-Blackwell. https://doi.org/10.1002/9781444346534

Jaspers, K. 1960. The idea of the university. London: Peter Owen.

- 1951. Man in the modern age. London: Routledge and Kegan Paul.

Jin, L. and Cortazzi, M. 2020. Reaching for the gold standard: Metaphors and good university teachers. Chinese Journal of Applied Linguistics 43(2): 131-149.

- 2016. Engineering the soul: Construction and sacrifice in the teaching profession in China and Iran. In Professions and metaphors: From turf battles to zoos and circuses, eds. A. Liljegren and M. Saks, 130-146. London: Routledge. https://doi. org/10.4324/9781315672045-9

- 2011a. More than a journey: "Learning" in the metaphors of Chinese students and teachers. In Researching Chinese learners: Skills, perceptions and intercultural adaptations, eds. L. Jin and M. Cortazzi, 67-92. Basingstoke: Palgrave Macmillan. https://doi.org/10.1057/9780230299481_4

- 2011b. The changing landscapes of a journey: Educational metaphors in China. In Education reform in China: Changing concepts, contexts and practices, ed. J. Ryan, 114-131. London: Routledge.

- 2008. Images of teachers, learning and questioning in Chinese cultures of learning. In Metaphors for learning, cross-cultural perspectives, ed. E. Berendt, 177-204. Amsterdam: John Benjamins. https://doi.org/10.1075/hcp.22.13jin

Kim, T. 2001. Forming the academic profession in East Asia, a comparative analysis. New York: Routledge.

Kövecses, Z. 2005. Metaphor in culture, universality and variation. Cambridge: Cambridge University Press. https://doi.org/10.1017/CBO9780511614408

Lakoff, G. and Johnson, M. 2003. Metaphors we live by. 2nd Ed. Chicago: The University of Chicago Press. https://doi.org/10.7208/chicago/9780226470993.001.0001 
Lee, M., Morshidi Sirat and Wan, C.D. 2017. The development of Malaysian universities, explaining characteristics emerging from interaction between Western academic models and traditional and local cultures. Higher Education and Development 11(1): 25-37. https://doi.org/10.1108/HEED-08-2017-004

McClelland, C.F. 1980. State, society and university in Germany 1700-1914. Cambridge: Cambridge University Press.

Milton, J. 1644. Aereopagitica, and Of education. Edited by G.H. Sabine. New York: Appleton Century-Crofts.

Moore, A. 2004. The good teacher: Dominant discourses in teaching and teacher education. London: Routledge. https://doi.org/10.4324/9780203420270

Newman, J.H.C. 1908. University teaching, considered in nine discourses. London: Longman, Green \& Co.

Nikitina, L. and Furuoka, F. 2008. “A language teacher is like...”: Examining Malaysia students' perceptions of language teachers through metaphor analysis. Electronic Journal of Language Teaching 5(2): 192-205.

Office for Students (OFS). 2020. National student survey - NSS. Retrieved from https:// www.officeforstudents.org.uk/advice-and-guidance/student-information-and-data/ national-student-survey-nss/.

Ortega y Gasset, J. 1944. Mission of the university. Translated by H.L. Nostrand. New York: Norton \& Co.

Östling, J. 2018. Humboldt and the modern German university. Translated by L. Olsson. Lund: Lund University Press.

Oxford, R.L., Tomlinson, S., Barcelos, A., Harrington, C., Lavine, R.Z., Saleh, A. and Longhina, A. 1998. Clashing metaphors about classroom teachers: Towards a systematic typology for the language teaching field. System 26(1): 3-50. https://doi. org/10.1016/S0346-251X(97)00071-7

Paz, O. 1990. The monkey grammarian [in Spanish]. Translated by H. Lane. New York: Arcade Publishing.

. 1982. Laureate's words of acceptance. World Literature Today 56(4): 595-596. https://doi.org/10.2307/40138153

Rohayati Che Din, Rajadurai, J. and Salina Daud. 2007. Establishing a student satisfaction index: A Malaysian case study. Paper presented at the 5th ASEAN Symposium on Educational Management and Leadership (ASEMAL 5), Kuala Lumpur, 18-19 August.

Simon, B. 1966. The history of education. In The study of education, ed. J.W. Tibble, 91-131. London: Routledge, Kegan Paul.

Teaching Excellence Framework (TEF). 2016. Teaching Excellence Framework: What you need to know. Retrieved from https://www.ucas.com/undergraduate/what-andwhere-study/choosing-course/teaching-excellence-framework-tef-what-you-needknow (accessed 9 July 2020).

Wan, C.D., Morshidi Sirat and Dzulkifli Abdul Razak. 2015. The idea of a university, rethinking the Malaysian context. Humanities 4(3): 266-282. https://doi. org/10.3390/h4030266

Wan, W. and Low, G., eds. 2015. Elicited metaphor analysis. Amsterdam: John Benjamins.

Warnock, M. 1989. Universities: Knowing our minds. London: Chatto and Windus. 